\title{
High apolipoprotein AI concentrations are associated with lower mortality and myocardial infarction five years after coronary artery bypass graft surgery
}

\author{
J S Skinner, M Farrer, C J Albers, H A W Neil, P C Adams
}

\begin{abstract}
Objective-To examine mortality and myocardial infarction five years after coronary artery bypass graft (CABG) surgery and the association with different lipid fractions and haemostatic, glycaemic, and demographic risk factors.

Setting-A regional cardiothoracic centre, Freeman Hospital, and the University Clinical Investigation Unit, Royal Victoria Infirmary, Newcastle upon Tyne, UK.

Design-353 consecutive patients (297 male, mean age $\mathbf{5 7 . 2}$ years) undergoing first time CABG for stable angina were recruited to a prospective cohort study and studied to five years.
\end{abstract}

Main outcome measures-All cause mortality, late cardiac mortality (beyond $\mathbf{3 0}$ days) alone and in combination with nonfatal myocardial infarction. Risk factor assessments before operation and 3, 6, 12, 24, and 60 months after surgery. For each laboratory variable a weighted mean for the period of exposure was calculated from the concentration at each time interval and the time between measurements. The distribution was divided into tertiles. Results-41 patients died (16 late cardiac deaths) and eight had a myocardial infarct. An adverse outcome occurred more frequently in the lower tertile of weighted apolipoprotein AI compared with the upper tertile. An adverse outcome was also more common in patients in the upper tertile of weighted total white blood cell count and less consistently so in patients in the upper tertile of the haemostatic covariates, factor VIIc and factor VIIIc. There was no association with other lipid fractions except for total mortality and apolipoprotein $B$ (owing to low levels in five patients with carcinoma).

Conclusions-Low apolipoprotein AI concentrations, but no other markers of an adverse lipid profile, were associated with mortality and myocardial infarction five years after CABG. Apolipoprotein AI is associated with paraoxonase, an enzyme located on high density lipoprotein, which may limit the oxidation of low density lipoprotein. An association between outcome and other covariates such as white cell count provides a credible pointer to inflammation mediating a component of cardiovascular risk.

(Heart 1999;81:488-494)
Keywords: coronary artery bypass graft surgery; mortality; myocardial infarction; apolipoprotein AI

It is now widely accepted that serum lipids are important in the development and progression of coronary artery disease. However, there is less agreement over which of the different lipid fractions and apolipoproteins best discriminate the patients at most risk. Serum high density lipoprotein (HDL) cholesterol concentration has been found to be inversely correlated with the development and progression of coronary artery disease. ${ }^{12}$ Apolipoprotein $\mathrm{AI}$ is a major lipoprotein in HDL cholesterol and its serum concentration discriminates patients with the highest coronary risk, ${ }^{34}$ although it may not be more predictive than serum HDL cholesterol. ${ }^{5}$ HDL removes excess cholesterol from peripheral tissues and transports it to the liver. However, more recent attention has focused on its role in reducing the oxidative modification of low density lipoprotein (LDL) and thus protecting against atherosclerosis. Recent evidence suggests that these effects are due to paraoxonase, ${ }^{6}$ an enzyme located on HDL and closely associated with apolipoprotein $\mathrm{AI}^{7}{ }^{7}$ Expression of apolipoprotein AII instead of apolipoprotein AI in transgenic mice is associated with a decreased content of paraoxonase and a loss of the antioxidant properties of HDL. ${ }^{8}$

HDL cholesterol and apolipoprotein AI concentrations have been less well studied in patients after coronary artery bypass graft surgery than in patients without surgery, although it is generally acknowledged that an adverse lipid profile is associated with a worse outcome after surgery. ${ }^{9-11}$ We designed a study to examine the outcome of unselected patients after coronary artery bypass graft surgery and to evaluate the association between risk factors and outcome. We studied 353 consecutive patients five years after elective surgery performed at a single surgical centre, and in this paper we report mortality and non-fatal myocardial infarction and the association with different lipid fractions, and other haemostatic, glycaemic, and demographic risk factors.

\section{Methods}

SUBJECTS

The study population has been described before. ${ }^{12}{ }^{13}$ Briefly, during the period 25 October 1988 to 4 December 1989, 367 consecutive patients were admitted for elective, first time 
coronary artery bypass graft surgery to the Freeman Hospital. Surgery was performed for chronic stable angina or after unstable angina had settled. Fourteen patients were excluded: eight lived outside the former Northern region, three had simultaneous valve surgery, and three refused to participate. Thus 353 patients (297 male, 56 female) consented and were recruited to this prospective study. The protocol for the study to five years was approved by the Newcastle joint ethics committee.

SURVIVAL STATUS

Five years after coronary artery bypass graft surgery, survival status was established for all patients. The date and cause of death was obtained from a review of hospital notes, necropsy reports, death certificates, and general practitioners. Sudden death was defined as a death occurring without previous symptoms or within one hour of the onset of new cardiac symptoms. ${ }^{14}$ An unwitnessed death was included in this group if the patient had been free of new symptoms for up to 24 hours before being found dead.

CLINICAL STATUS AND RISK FACTOR ASSESSMENT Patients were seen preoperatively, and three, six, 12, 24, and 60 months after surgery. Clinical status was evaluated. Hospital admissions were corroborated from the notes. Preoperative hypertension was defined when the patient was previously diagnosed as hypertensive, whether treated or not, and in any patients in whom the systolic blood pressure was higher than 160 $\mathrm{mm} \mathrm{Hg}$ or diastolic blood pressure higher than $90 \mathrm{~mm} \mathrm{Hg}$, measured after 10 minutes of rest. A significant family history of premature coronary disease was defined as any first degree relative with ischaemic heart disease aged 55 years or less.

Blood samples were obtained during each visit from patients after a 12 hour overnight fast. Total cholesterol, triglyceride, apolipoprotein $\mathrm{AI}$, and apolipoprotein B concentrations were determined from serum samples and insulin concentration from stored serum samples. HDL cholesterol concentration was measured in EDTA/plasma and plasma glucose concentration from fluoride oxalate samples. Lp(a) lipoprotein concentration was determined from stored serum samples. Haemostatic factors included fibrinogen concentration, factor VII coagulant activity (FVIIc), and factor VIII coagulant activity (FVIIIc), and were determined from stored citrated plasma samples. Haemoglobin concentration, total white blood cell count, and platelet count were determined from EDTA samples.

Venous plasma glucose concentration was measured with a glucose analyser (Yellow Springs Instruments, Ohio, USA). An aqueous phase glucose standard $(10 \mathrm{mmol} / \mathrm{l})$ and three reference samples were used for quality assurance.

Serum insulin was measured by a standard radioimmunoassay ${ }^{15}$ (interassay coefficient of variation (cv), $1.7 \%$ to $7.5 \%$ ).

Standard enzymatic methods were used to measure serum cholesterol (cholesterol oxi- dase, interassay $\mathrm{cv}, 1.3 \%$ to $2.1 \%$ ) and triglycerides (lipase-glycerol kinase; interassay $\mathrm{cv}$, $2.7 \%$ to $9.4 \%$ ). HDL cholesterol was measured after precipitation of apolipoprotein B containing lipoproteins with heparin and manganese or with phosphotungstate and magnesium, and assayed by the cholesterol oxidase method (interassay cv, 8.8\% to $14.6 \%$ ). Values obtained with the phosphotungstate and magnesium method were adjusted to be equivalent to those obtained with the heparin and manganese method using the following regression equation: (phosphotungstate and magnesium method) $=0.99 \times$ (heparin and manganese method) -0.07 . LDL cholesterol was calculated from the Friedewald equation. ${ }^{16}$

Apolipoprotein AI and apolipoprotein B were measured with a rate immunonephelometric assay (Technicon DPA, Technicon Instruments, Basingstoke, UK; interassay cv, $4.9 \%$ to $7.3 \%$ ).

$\mathrm{Lp}$ (a) lipoprotein was measured by an enzyme linked immunosorbent assay (ELISA, Biopool, Umea, Sweden; interassay cv, 3\% to $8 \%$ ).

Full blood counts were performed using a Coulter counter (Coulter STKS; interassay cv, haemoglobin $0.6 \%$ to $0.8 \%$, white blood cell count $1.0 \%$ to $1.7 \%$, platelet count $1.6 \%$ to $3.3 \%)$.

Fibrinogen concentration was measured from a derived fibrinogen method based on prothrombin time using IL-PT-HS plus thromboplastin (ACL Futura, Instrumentation Laboratory, Milan, Italy). Two reference samples of low and medium concentration were used for quality assurance. FVIIc was measured using a one stage clotting assay based on prothrombin time using IL-PT-HS plus thromboplastin; FVIIIc was measured using a one stage clotting assay based on activated partial thromboplastin time using IL-lyophilised silica (ACL Futura, Instrumentation Laboratory). Factor VIIc and factor VIIIc were expressed as percentages of reference plasma calibrated against a standard for factor VIIc and factor VIIIc, respectively.

DATA HANDLING AND STATISTICAL ANALYSIS Data manipulation and analyses was performed using two statistical packages, Statview (Abacus Concepts, Berkeley, California, USA) and STATA 3.1 (STATA Corporation, College Station, Texas, USA).

Categorical variables were expressed as the number (\%) and continuous variables as the mean (SD) if distributed normally; otherwise as the median (interquartile range).

Age was categorised into 10 year age groups for analysis. Laboratory variables and body mass index were measured before surgery and at the stated intervals afterwards. For each laboratory variable the mean of measurements made at two consecutive time points was related to the duration of time between those points and thus, using all the consecutive measurements, an overall weighted mean for the time period was obtained. 
Table 1 Potential covariates for outcome considered in univariate and multivariate analyses

\begin{tabular}{l} 
Sex \\
Age \\
Extent of preoperative coronary disease \\
Left ventricular regional wall motion abnormalities \\
Preoperative hypertension \\
Smoking habits \\
Preoperative diabetes \\
Preoperative myocardial infarction \\
Family history of premature coronary artery disease \\
Lp(a) lipoprotein \\
Fibrinogen \\
Factor VIIc \\
Factor VIIIc \\
Haemoglobin \\
White blood cell count \\
Platelet count \\
Fasting plasma glucose \\
Fasting serum insulin \\
Non-HDL cholesterol (total cholesterol - HDL cholesterol) \\
HDL cholesterol \\
Triglycerides \\
Apolipoprotein AI \\
Apolipoprotein B \\
Body mass index \\
Non-use of a LIMA conduit \\
\hline HDL, high density lipoprotein; LIMA, left internal mammary \\
artery.
\end{tabular}

For example, weighted mean total cholesterol $=[(3 \times(\mathrm{a}+\mathrm{b}) / 2)+(3 \times(\mathrm{b}+\mathrm{c}) / 2)+$ $(6 \times(c+d) / 2)+(12 \times(d+e) / 2)+(36 \times(e+f) / 2] / 60$ where $a, b, c, d, e$, and $f$ are the total cholesterol concentration before surgery and 3, 6, 12, 24, and 60 months after surgery.

If patients died, weighted means were calculated for the duration of time until death. If patients alive after five years had missing measurements, a weighted mean was calculated from those measurements available for that time period. The distribution of some weighted means was highly skewed and therefore all weighted means were categorised into tertiles.

The potential covariates for outcome are shown in table 1. Most categorical covariates with the exception of smoking status were binary variables and two binary covariates were created to identify smoking status. One identified patients as ex-smokers or otherwise, and the other as current smokers or otherwise. A person who had never smoked would be thus be coded zero in both.

Clinical event-free survival was estimated with life table methods. Patients undergoing repeat cardiac surgery were censored at the time of the second operation. The log-rank test and the log-rank test for trend were used to compare survival probabilities and the appropriate $\chi^{2}$ statistic produced. Deaths within 30 days of surgery were treated as censored in the analysis of late cardiac death and major events. Hazard ratios are referred to as the relative risk with appropriate $95 \%$ confidence intervals (CI). For covariates analysed in tertiles, the relative risk is that of the third tertile compared with the first. Using the Cox proportional hazards model, a forward selection procedure evaluated the independent influence of covariates on total mortality and late major cardiac events. To avoid including different lipid variables which are clearly interdependent, two possible models were examined in multivariate analysis. Model 1 included non-HDL cholesterol, HDL choles-
Table 2 Clinical characteristics before coronary artery bypass graft surgery

\begin{tabular}{ll}
\hline Male & $297(84)$ \\
Age (years) (mean (SD)) & $57.2(7.3)$ \\
Angina & $337(98)$ \\
Hypertension & $133(38)$ \\
Diabetes & $22(6)$ \\
History of hypercholesterolaemia & $121(35)$ \\
Obesity (BMI > $\left.25 \mathrm{~kg} / \mathrm{m}^{2}\right)$ & $214(61)$ \\
Never smoked & $57(16)$ \\
Ex cigarette smoker & $278(80)$ \\
Smoker at operation & $11(3)$ \\
History of stroke/TIA & $18(5)$ \\
History of claudication & $58(17)$ \\
Previous myocardial infarction & $215(61)$ \\
History of heart failure & $19(5)$ \\
Renal disease (dialysis or transplant) & $4(1)$ \\
\hline
\end{tabular}

Values are n (\%) unless otherwise stated.

$\mathrm{BMI}$, body mass index; TIA, transient ischaemic attack.

terol, and triglycerides, but not apolipoprotein AI and apolipoprotein B. Model 2 included apolipoprotein AI and apolipoprotein B, but not non-HDL cholesterol, HDL cholesterol, and triglycerides. The remaining covariates were considered in both models. Total cholesterol, LDL cholesterol, and the ratio of total cholesterol to HDL cholesterol were also examined in univariate analysis. Where there were missing data (never more than $10 \%$ ), the analysis was performed on the population sample excluding missing values. An $\alpha$ level of $5 \%$ was taken as significant.

\section{Results}

PATIENT CHARACTERISTICS BEFORE OPERATION AND OPERATION DETAILS

The preoperative clinical and angiographic characteristics of the 353 patients studied are summarised in tables 2 and 3. There were 297 male patients and 56 female. Mean (SD) age at the time of surgery was $57.2(7.3)$ years. Thirty eight per cent of the patients had hypertension and $6 \%$ diabetes. More than $60 \%$ had a history of preoperative myocardial infarction and $5 \%$ a history of heart failure. Ninety eight per cent reported recent angina, $73 \%$ with severe (grade III or IV) symptoms.

Table 3 Severity of coronary artery disease ${ }^{\star}$ and operation details

\begin{tabular}{ll}
\hline Single vessel disease & $68(20)$ \\
Two vessel disease & $138(40)$ \\
Three vessel disease & $94(27)$ \\
Left main stem disease & $45(13)$ \\
Normal left ventricle & $141(41)$ \\
Only hypokinetic LV segments & $101(29)$ \\
Akinetic or dyskinetic LV segment & $101(29)$ \\
Number of graft conduits (mean (SD)) & $2.74(0.77)$ \\
Number of distal anastomoses (mean (SD)) & $3.6(1.20)$ \\
Patients with vein graft & $332(94)$ \\
Patients with LIMA & $266(75)$ \\
Patients with RIMA & $46(13)$ \\
Patients with graft to LAD & $311(88)$ \\
Patients with graft to diagonal & $220(62)$ \\
Patients with graft to circumflex & $269(76)$ \\
Patients with graft to intermediate & $16(5)$ \\
Patients with graft to right coronary artery & $281(80)$ \\
\hline
\end{tabular}

Values are $\mathrm{n}(\%)$ unless otherwise stated.

* Significant coronary artery disease is defined as reduction in artery luminal diameter of $75 \%$ or more in an epicardial coronary artery or a major branch supplying at least $25 \%$ of either the left anterior descending and diagonal territory, the circumflex territory, or the inferior territory (or $50 \%$ if left main stem).

$\mathrm{LAD}$, left anterior descending coronary artery; LIMA, left internal mammary artery; LV, left ventricular; RIMA, right internal mammary artery. 
Table 4 Covariates significantly associated with outcome after coronary artery bypass graft surgery in univariate analysis

\begin{tabular}{|c|c|c|c|c|c|}
\hline & \multicolumn{3}{|l|}{ Tertiles/groups } & \multirow[b]{2}{*}{$p$ Value } & \multirow[b]{2}{*}{$R R(95 \% C I)$} \\
\hline & 1 & 2 & 3 & & \\
\hline \multicolumn{6}{|l|}{ All cause mortality $(\mathrm{n}=68)$} \\
\hline Apolipoprotein $\mathrm{AI}^{\star}$ & 19 & 13 & 7 & $<0.05$ & $0.37(0.16$ to 0.89$)$ \\
\hline Haemoglobin & 21 & 12 & 8 & $<0.01$ & $0.36(0.16$ to 0.82$)$ \\
\hline White blood cell count & 6 & 15 & 20 & $<0.01$ & $3.51(1.41$ to 8.75$)$ \\
\hline FVIIc $^{\star}$ & 8 & 11 & 21 & $<0.01$ & $2.76(1.22$ to 6.24$)$ \\
\hline FVIIIc* & 10 & 10 & 20 & $<0.05$ & $2.11(0.99$ to 4.50$)$ \\
\hline Female sex & $30 / 257(12 \%)$ & $11 / 56(20 \%)$ & & $<0.05$ & $2.10(1.05$ to 4.19$)$ \\
\hline Preoperative hypertension & $18 / 220(8 \%)$ & $23 / 133(17 \%)$ & & $<0.01$ & $2.22(1.20$ to 4.11$)$ \\
\hline \multicolumn{6}{|l|}{ Late cardiac death $(\mathrm{n}=16)$} \\
\hline Apolipoprotein AI & 8 & 7 & 1 & $<0.05$ & $0.13(0.02$ to 1.01$)$ \\
\hline Haemoglobin & 9 & 5 & 2 & $<0.05$ & $0.20(0.04$ to 0.95$)$ \\
\hline White blood cell count & 2 & 4 & 10 & $<0.05$ & $5.33(1.17$ to 24.37$)$ \\
\hline Preoperative LV RWM & $3 / 141(2 \%)$ & $3 / 101(3 \%)$ & $10 / 101(10 \%)$ & $<0.01$ & 4.86 (1.34 to 17.67$)$ \\
\hline Female sex & $10 / 257(4 \%)$ & $6 / 56(11 \%)$ & & $<0.01$ & $3.52(1.28$ to 9.68$)$ \\
\hline Preoperative hypertension & $6 / 220(3 \%)$ & $10 / 133(8 \%)$ & & $<0.05$ & $2.95(1.07$ to 8.13$)$ \\
\hline \multicolumn{6}{|c|}{ Late cardiac death/non-fatal MI $(\mathrm{n}=23)$} \\
\hline Triglycerides $\star$ & 2 & 8 & 12 & $<0.01$ & $6.51(1.46$ to 29.07$)$ \\
\hline Apolipoprotein AI & 11 & 9 & 3 & $<0.05$ & $0.27(0.08$ to 0.98$)$ \\
\hline FVIIIc & 5 & 5 & 13 & $<0.05$ & 2.81 (1.00 to 7.88$)$ \\
\hline White blood cell count & 5 & 5 & 13 & $<0.05$ & $2.82(1.01$ to 7.92$)$ \\
\hline Preoperative LV RWM & $6 / 141(4 \%)$ & $5 / 101(5 \%)$ & $11 / 101(10 \%)$ & $<0.05$ & $2.67(0.99$ to 7.21$)$ \\
\hline Non-use of LIMA & $12 / 266(5 \%)$ & $11 / 87(13 \%)$ & & $<0.01$ & $0.34(0.15$ to 0.78$)$ \\
\hline Female sex & $16 / 257(6 \%)$ & $7 / 56(13 \%)$ & & $<0.05$ & $2.56(1.05$ to 6.21$)$ \\
\hline Preoperative hypertension & $8 / 220(4 \%)$ & 15/133 (11\%) & & $<0.01$ & 3.37 (1.43 to 7.96$)$ \\
\hline
\end{tabular}

For categorical variables, group $1=-$ covariate, group $2=+$ covariate. For covariates analysed in tertiles, the RR is that of the third tertile compared with the first, and for LV RWM that of group 3 compared with group 1.

$\star$ One or two patients with events had no assays performed for these variables.

CI, confidence interval; LIMA, left internal mammary artery conduit; LV RWM, left ventricular regional wall motion abnormalities (in group 1 there are no regional wall motion abnormalities, in group 2 hypokinetic segments only, and in group 3 akinetic or dyskinetic segments were also present); RR, relative risk.

More than one quarter had three vessel disease and $13 \%$ left main stem disease. Left ventricular function, assessed in the $30^{\circ}$ right anterior oblique projection, was normal in $41 \%$ patients, $29 \%$ patients had only hypokinetic segments, while in $29 \%$ akinetic or dyskinetic segments were also present.

A left internal mammary artery (LIMA) conduit was used in $75 \%$ of patients, and in

Table 5 Covariates independently associated with outcome after coronary artery bypass graft surgery in multivariate analysis

\begin{tabular}{|c|c|c|c|}
\hline & $\beta$ & $S E \beta$ & p Value \\
\hline \multicolumn{4}{|l|}{ All cause mortality } \\
\hline \multicolumn{4}{|l|}{ Model 1} \\
\hline FVIIc & 0.6603 & 0.2296 & $<0.01$ \\
\hline Preoperative hypertension & 0.9075 & 0.3487 & $<0.01$ \\
\hline \multicolumn{4}{|l|}{ Model 2} \\
\hline FVIIc & 0.9034 & 0.2433 & $<0.001$ \\
\hline Apolipoprotein AI & -0.7481 & 0.2315 & $<0.001$ \\
\hline Preoperative hypertension & 0.8378 & 0.3421 & $<0.05$ \\
\hline Apolipoprotein B & -0.4479 & 0.2160 & $<0.05$ \\
\hline \multicolumn{4}{|l|}{ Late cardiac death } \\
\hline \multicolumn{4}{|l|}{ Model 1} \\
\hline Female sex & 1.5125 & 0.5597 & $<0.01$ \\
\hline Preoperative LV RWM & 0.9485 & 0.3722 & $<0.01$ \\
\hline White blood cell count & 0.9369 & 0.4019 & $<0.05$ \\
\hline \multicolumn{4}{|l|}{ Model 2} \\
\hline Female sex & 1.4307 & 0.5429 & $<0.01$ \\
\hline Preoperative LV RWM & 1.02737 & 0.3797 & $<0.01$ \\
\hline Apolipoprotein AI & -0.7728 & 0.3706 & $<0.05$ \\
\hline White blood cell count & 0.8126 & 0.3765 & $<0.05$ \\
\hline \multicolumn{4}{|c|}{ Late cardiac death or non-fatal MI } \\
\hline \multicolumn{4}{|l|}{ Model 1} \\
\hline Use of LIMA & -1.3132 & 0.4744 & $<0.01$ \\
\hline Preoperative hypertension & 1.2998 & 0.4958 & $<0.01$ \\
\hline Fasting insulin & 0.7164 & 0.3398 & $<0.05$ \\
\hline \multicolumn{4}{|l|}{ Model 2} \\
\hline Use of LIMA & -1.3600 & 0.4519 & $<0.01$ \\
\hline Preoperative hypertension & 1.2463 & 0.4699 & $<0.01$ \\
\hline Preoperative LV RWM & 0.6288 & 0.2796 & $<0.05$ \\
\hline Apolipoprotein AI & -0.6001 & 0.3013 & $<0.05$ \\
\hline
\end{tabular}

See text for covariates included in the two models.

LIMA, left internal mammary artery conduit; LV RWM, left ventricular regional wall motion abnormalities. only $6 \%$ patients were internal mammary artery grafts the only conduits used.

\section{MORTALITY}

The mortality status is known for all patients. Forty one patients died within five years of surgery and three had further cardiac surgery, one undergoing cardiac transplantation 45 months after initial grafting and two undergoing redo coronary artery bypass surgery at nine and 51 months after initial surgery, respectively. The actuarial survival of patients without further cardiac surgery 60 months after surgery was $87 \%$.

\section{Mortality beyond 30 days}

Twenty seven patients died between 30 days and 60 months after surgery. Sixteen of these deaths were cardiac deaths, of which 10 were sudden and five were caused by acute myocardial infarction. One death was unwitnessed in a patient who had a recent episode of unstable angina. Eleven patients died from non-cardiac causes: seven from malignant disease, three from vascular pathology, and one (an immunosuppressed patient) from infection.

NON-FATAL MYOCARDIAL INFARCTION

During the five years since coronary artery bypass surgery, seven survivors were admitted with a non-fatal myocardial infarct. One of these patients had been admitted twice and one three times with acute infarction. Of the 44 patients who had died or required further surgery, only one had a non-fatal infarct, which occurred 12 months before death. Hence overall, eight patients suffered at least one postoperative non-fatal infarct, and $98 \%$ of them survived free from an admission with non-fatal infarction 60 months after surgery. 
ALL CAUSE MORTALITY

Univariate analysis

All cause mortality was associated with high concentrations of factor VIIc and factor VIIIc, high white blood cell count, low concentration of haemoglobin and apolipoprotein AI, preoperative hypertension, and female sex (table 4).

\section{Multivariate analysis}

In multivariate analysis, factor VII and preoperative hypertension were included in model 1 , and in addition, apolipoprotein AI and apolipoprotein B were also included in model 2 (table 5).

\section{LATE CARDIAC MORTALITY BEYOND 30 DAYS}

Univariate analysis

Late cardiac death was associated with low concentrations of apolipoprotein AI and haemoglobin, high white blood cell count, more severe left ventricular regional wall motion abnormalities, preoperative hypertension, and female sex (table 4).

\section{Multivariate analysis}

In multivariate analysis, female sex, more severe left ventricular regional wall motion abnormalities, and white blood cell count were included in model 1, and in addition, apolipoprotein AI was also included in model 2 (table 5).

LATE CARDIAC MORTALITY AND NON-FATAL MYOCARDIAL INFARCTION

Univariate analysis

The combination of late cardiac death and nonfatal myocardial infarction was associated with high concentrations of triglycerides and factor VIIIc, a high white blood cell count, low concentrations of apolipoprotein AI, more severe left ventricular regional wall motion abnormalities, preoperative hypertension, non-use of a LIMA conduit, and female sex (table 4).

\section{Multivariate analysis}

In multivariate analysis, non-use of a LIMA conduit, preoperative hypertension, and fasting insulin were included in model 1 , and non-use of an LIMA conduit, preoperative hypertension, more severe left ventricular regional wall motion abnormalities, and apolipoprotein AI in model 2 (table 5).

\section{Discussion}

We designed this study to evaluate prospectively the outcome of a consecutive group of unselected patients five years after coronary artery bypass graft surgery, and to examine the association with coronary risk factors. To the best of our knowledge it is the first to include lipid, haemostatic, glycaemic, and demographic risk factors. We have found a direct and independent association between apolipoprotein AI concentration and all cause mortality and late cardiac events. There was no association between outcome and any other lipid fractions with the exception of that between all cause mortality and apolipoprotein B concentration.
There are few studies which have prospectively examined the association between major events after coronary artery bypass graft surgery and different lipid fractions, although the association with angiographic outcome is more widely reported. Ten years after surgery patients with recurrent cardiac events had higher serum concentrations of total cholesterol and triglycerides, but there was no association with HDL cholesterol, apolipoprotein AI, or apolipoprotein $\mathrm{B},{ }^{9}$ and in multivariate analysis an adverse outcome was particularly found in patients with the combination of low HDL cholesterol and high triglycerides. ${ }^{9}$ High concentrations of total cholesterol and triglycerides discriminated patients with severe angina from those without angina five years after coronary artery bypass graft surgery. ${ }^{17}$ In angiographic studies, late changes in vein grafts and in native coronary arteries were associated with low levels of HDL cholesterol, ${ }^{11}$ early ${ }^{18}$ and late ${ }^{19}$ vein graft occlusions were associated with higher levels of total cholesterol, and late thrombosis of vein grafts was associated with higher ratios of serum total cholesterol to HDL cholesterol and of serum LDL cholesterol to HDL cholesterol. ${ }^{20}$ In randomised controlled trials, progression of atherosclerosis in vein grafts was less in patients treated with lipid lowering drugs, ${ }^{10}$ and more aggressive lowering of LDL cholesterol had the greatest impact. ${ }^{21}$

There was a strong association between outcome and apolipoprotein AI concentration in our study - there was a threefold increase in risk of late major coronary events in patients in the bottom tertile compared to those in the top tertile. In contrast, we have not found an association between major events and other markers of an adverse lipid profile. Apolipoprotein AI has a major role in the function of HDL to remove excess cholesterol from peripheral tissues and may be a better marker of adverse cholesterol metabolism than the other lipid fractions analysed. Alternatively, the association we found between outcome and the concentration of apolipoprotein AI may reflect its physical association with paraoxonase, an enzyme located on HDL which reduces oxidative modification of LDL, ${ }^{6}$ and thus may protect against atherosclerosis.

Low concentrations of apolipoprotein AI have been associated with $\beta$ blocker treatment. In our study, there was no significant difference in mean apolipoprotein AI concentration in patients taking $\beta$ blockers and those not taking them (preoperation, $1.0 \mathrm{~g} / 1 \vee 1.0 \mathrm{~g} / 1$; at five years, $1.4 \mathrm{~g} / 1 v 1.5 \mathrm{~g} / \mathrm{l})$. Hence, the association between low apolipoprotein AI concentration and all measures of outcome was not explained by a greater use of $\beta$ blockers in patients with an adverse outcome.

High levels of markers of systemic inflammation have been associated with later myocardial infarction in healthy $\operatorname{men}^{22}$ and acute coronary events in patients with angina. ${ }^{23}$ In our study the total white blood cell count was associated with mortality, and myocardial infarction and may be a marker of inflammation. We have also found less 
consistent associations between outcome and the haemostatic covariates FVIIc and FVIIIc and haemoglobin concentration. However, in contrast to patients with native coronary disease, ${ }^{22}{ }^{23}$ high concentrations of fibrinogen were not associated with an adverse outcome in our study (events in tertiles 1, 2, and 3 for fibrinogen, respectively: all cause mortality, 11, 14, 15; late cardiac death, 3, 7, 6; late cardiac death and myocardial infarction, $5,11,7)$.

C reactive protein is an acute phase reactant and a marker for underlying systemic inflammation. Moreover, raised concentrations have been reported in patients developing acute coronary syndromes, ${ }^{22}{ }^{23}$ and discriminate patients with unstable angina who have a worse outcome. ${ }^{24}$ Unfortunately we do not know the C reactive protein concentrations in our patients.

The association between a low concentration of apolipoprotein B and all cause mortality was a surprise. Apolipoprotein B is the major protein of LDL and previous studies have reported an association between high apolipoprotein $\mathrm{B}$ concentration and adverse angiographic outcome after coronary artery bypass graft surgery. ${ }^{1125}$ However, further scrutiny showed that this apparent anomaly in our study is explained by very low concentrations of apolipoprotein B in five patients dying from carcinoma.

Our study is robust and has reaffirmed preoperative left ventricular dysfunction ${ }^{26-33}$ and hypertension ${ }^{27}{ }^{34}$ as predictors of mortality. Sex has also previously been identified as an independent predictor of late mortality after coronary artery surgery, ${ }^{35}$ although others have failed to confirm this if other variables were considered $^{3637}$ and operative mortality was excluded..$^{38}$ However, covariates for which we have found no association with outcome may have a weaker association than we are able to detect. For example, the adverse effect on survival of patients with more extensive preoperative coronary artery disease is well described,,$^{26} 34$ and compared with older patients, a survival advantage has been reported in younger patients which persisted with prolonged periods of follow up. ${ }^{27}{ }^{34} \mathrm{We}$ estimate that the smallest detectable difference in total mortality between the upper and lower tertiles of the laboratory variables represents a relative risk of approximately 2.0 .

\section{CONCLUSIONS}

Our study reaffirms the importance of the previously identified risk factors of female sex, preoperative hypertension, and left ventricular dysfunction as predictors of outcome five years after coronary artery bypass graft surgery. However, more importantly we have found a consistent and independent association between low concentrations of apolipoprotein AI and an adverse outcome. An association between outcome and other covariates such as total white blood cell count provides a credible pointer to inflammation mediating a component of cardiovascular risk. There is increasing attention focused on the role of inflammatory atherosclerosis in patients with native coronary disease and our results emphasise that the role of inflammatory atherosclerosis after coronary artery bypass graft surgery also needs to be investigated.

This study was supported by a grant from The British Heart Foundation. MF held a Wellcome Junior Clinical Research Fellowship and JSS held a Research Training Fellowship awarded by the Research and Development Division of the Northern Region. We are grateful for the support of Professor R W F Campbell, $\mathrm{Mr} \mathrm{J} \mathrm{H} \mathrm{Dark,} \mathrm{and} \mathrm{all} \mathrm{the} \mathrm{cardiologists} \mathrm{and}$ cardiothoracic surgeons whose patients have been studied, and to Ms Nicola Cleghorn for technical assistance. Professor Campbell sadly died during the time this paper was being submitted.

1 Pocock SJ, Shaper AG, Phillips AN. Concentrations of high density lipoprotein cholesterol, triglycerides, and total cholesterol in ischaemic heart disease. BMF 1989;298:9981002 .

2 Castelli WP, Garrison RJ, Wilson PW, et al. Incidence of coronary heart disease and lipoprotein cholesterol levels. The Framingham study. $7 A M A$ 1986;256:2835-8.

3 Garfagnini A, Devoto G, Rosselli P, et al. Relationship between HDL cholesterol and apolipoprotein AI and the severity of

4 Sigurdsson G, Baldursdottir A, Sigvaldason H, et al. Predictive value of apolipoproteins in a prospective survey of coronary artery disease in men. Am f Cardiol 1992;69:1251-4.

5 Rader DJ, Hoeg JM, Brewer HB. Quantitation of plasma apolipoproteins in the primary and secondary prevention of coronary artery disease. Ann Intern Med 1994;120:101225.

6 Watson AD, Berliner JA, Hama SY, et al. Protective effects of high density lipoprotein associated paraoxonase. Inhibition of the biological activity of minimally oxidised low density lipoprotein. F Clin Invest 1995;96:2882-91.

7 Mackness MI, Mackness B, Durrington PN, et al. Paraoxonase: biochemistry, genetics and relationship to plasma lipoproteins. Curr Opin Lipidol 1996;7:69-76.

8 Clasma lipoproteins. Curr Opin Lipidol 1996;7:69-76. Castellani LW, Navab M, Van Lenten BJ, et al. Overexpres-
sion of apolipoprotein AII in transgenic mice converts high sion of apolipoprotein AII in transgenic mice converts high density lipoproteins to $\mathrm{p}$
Invest 1997;100:464-74.

9 Linden T, Bondjers G, Karlsson T, et al. Serum triglycerides and HDL cholesterol - major predictors of long-term survival after coronary surgery. Eur Heart $\mathcal{F}$ 1994;15:747-52.

10 Blankenhorn DH, Nessim SA, Johnson RL, et al. Beneficial effects of combined colestipol-niacin therapy on coronary atherosclerosis and coronary venous bypass grafts. $\mathscr{F} A M A$ 1987;257:3233-40.

11 Campeau L, Enjalbert M, Lesperance J, et al. The relation of risk factors to the development of atherosclerosis in saphenous-vein bypass grafts and the progression of disease in the native circulation. A study 10 years after aortocoronary bypass surgery. N Engl f Med 1984;311:1329-32.

12 Farrer M, Skinner JS, Albers CJ, et al. Outcome after coronary artery surgery in women and men in the north of England. $Q \mathcal{F}$ Med 1997;90:203-11.

13 Skinner JS, Farrer M, Albers CJ, et al. Serum Lp(a) lipoprotein concentration is not associated with clinical and angio-
graphic outcome five years after coronary artery bypass graphic outcome five years after corc

14 Gillum RF, Fortmann SP, Prineas RJ, et al. International diagnostic criteria for acute myocardial infarction and acute stroke. Am Heart f 1984;108:150-8

15 Soeldner JS, Slone D. Critical variables in the radioimmunoassay of serum insulin using the double antibody technic. Diabetes 1965;14:771-9.

16 Friedewald WT, Levy RI, Fredrickson DS. Estimation of concentration of low density lipoprotein cholesterol in plasma, without use of the preparative ultricentrifuge. Clin Chem 1972;18:499-502.

17 Yli-Mayry S, Huikuri HV. Clinical and angiographic prediction of myocardial infarction and recurrence of severe angina during a five-year follow-up after coronary artery angina during a five-year follow-up after coro
bypass grafting. Am 7 Cardiol 1993;72:1371-5.

18 Blumlein SL, Anderson AJ, Barboriak JJ, et al. Preoperative Blumlein SL, Anderson AJ, Barboriak J , et al. Preoperative
risk factors and aorta-coronary bypass graft patency. $\mathcal{f}$ Thorac Cardiovasc Surg 1976;72:778-83.

19 Daida H, Yokoi H, Miyano H, et al. Relation of saphenous vein graft obstruction to serum cholesterol levels. $\mathcal{F} \mathrm{Am}$ Coll Cardiol 1995;25:193-7

20 Solymoss BC, Nadeau P, Millette D, et al. Late thrombosis of saphenous vein coronary bypass grafts related to risk factors. Circulation 1988;78 (suppl 1):I-140-3

21 The Post Coronary Artery Bypass Graft Trial Investigators. The effect of aggressive lowering of low density lipoprotein cholesterol levels and low dose anticoagulation on obstructive changes in saphenous-vein coronary-artery bypass grafts. N Engl f Med 1997;336:153-62.

22 Ridker PM, Cushman M, Stampfer MJ, et al. Inflammation, aspirin, and the risk of cardiovascular disease in apparently healthy men. N Engl f Med 1997;336:973-9.

23 Thompson SG, Kienast J, Pyke S, et al. Hemostatic factors and the risk of myocardial infarction or sudden death in patients with angina pectoris. N Engl F Med 1995;332:635- 
24 Liuzzo G, Biasucci LM, Gallimore R, et al. The prognostic value of C-reactive protein and serum amyloid A protein in
severe unstable angina. $N$ Engl 7 Med 1994;331:417-24.

25 Campeau L, Enjalbert M, Lesperance J, et al. Atherosclerosis and late closure of aortocoronary saphenous vein grafts: sequential angiographic studies at 2 weeks, 1 year, 5 to 7 years, and 10 to 12 years after surgery. Circulation 1983;68(suppl II):II-1-7.

26 Rahimoola SH, Fessler CL, Grunkemeier GL, et al. Survival 15 to 20 years after coronary bypass surgery for angina. $f$ Am Coll Cardiol 1993;21:151-7.

27 Smith LR, Harrell FE, Rankin JS, et al. Determinants of early versus late cardiac death in patients undergoing coronary artery bypass graft surgery. Circulation 1991, 84(suppl III):III-245-53.

28 Stahle E, Bergstrom R, Holmberg L, et al. Survival after coronary artery bypass grafting. Experience from 4661

29 Kirklin JW, Naftel CD, Blackstone EH, et al. Summary of a consensus concerning death and ischemic events after coronary artery bypass grafting. Circulation 1989;79(suppl onary artery

30 Adler DS, Goldman L, O'Neil A, et al. Long-term survival of more than 2,000 patients after coronary artery bypass grafting. Am f Cardiol 1986;58:195-202.

31 Varnauskas E, and the European Coronary Surgery Study Group. Twelve year follow up of survival in the randomized European coronary surgery study. $N$ Engl f Med 1988;319: 332-7.
32 CASS Principal Investigators and their Associates. Coronary artery surgery study (CASS): a randomized trial of coronary artery bypass surgery. Survival data. Circulation 1983;68:939-50.

33 Detre KM, Takaro $\mathrm{T}$, Hultgren $\mathrm{H}$, et al. Long term mortality and morbidity results of the Veterans Administration randomized trial of coronary artery bypass surgery. Circulation 1985;72(suppl V):V-84-9.

34 Lawrie GM, Morris GC, Earle N. Long-term results of coronary bypass surgery. Analysis of 1698 patients followed 15 to 20 years. Ann Surg 1991;213:377-85.

35 Cameron A, Kemp HG, Green GE. Bypass surgery with the internal mammary graft: 15 year follow up. Circulation 1986;74(suppl III):III-30-6.

36 Douglas JS, King SB, Jones EL, et al. Reduced efficacy of coronary bypass surgery in women. Circulation 1981; 64(suppl II):II-11-16.

37 Rahimtoola SH, Bennett AJ, Grunkemeier GL, et al. Survival at 15 to 18 years after coronary bypass surgery for angina in women. Circulation 1993;88(suppl II):II-71-8.

38 Loop FD, Golding LR, MacMillan JP, et al. Coronary artery surgery in women compared with men: analyses of risks and long-term results. 7 Am Coll Cardiol 1983;1:38390.

39 van Brussel BL, Plokker HW, Ernst SM, et al. Venous coronary artery bypass surgery. A 15 -year follow-up study. Circulation 1993;88(suppl II):II-87-92. 